\title{
IMBALANCE OF INTESTINAL IMMUNE FUNCTION IN PIGLETS INFECTED BY PORCINE CIRCOVIRUS TYPE 2 DURING THE FETAL PERIOD
}

\author{
$\mathrm{Yu} \mathrm{MAO}^{+}$, Jin Jun $\mathrm{LI}^{+}$, Yuan LIU, Wei Dong, Pei PANG and Zhi Bang DenG ${ }^{*}$ \\ College of Veterinary Medicine, Hunan Agricultural University, Changsha, \\ Hunan 410128, P. R. China
}

(Received 23 May 2016; accepted 2 November 2016)

\begin{abstract}
Porcine circovirus type 2- (PCV2-) associated reproductive disorders and enteritis have commonly been observed on PCV2-contaminated pig farms in recent years. In order to investigate disorders of intestinal immunity in piglets infected by PCV2 during the fetal period, 9 PCV2b-infected piglets and 6 noninfected piglets at one day of age were selected and euthanised prior to suckling. Samples of mesenteric lymph nodes (MLNs) and duodena were collected to investigate factors related to intestinal immunity and to detect lymphocytic apoptosis. The results indicated that there were no significant changes in the levels of IL-2, IL-10 and transforming growth factor- $\beta$ (TGF- $\beta$ ) in the PCV2b-infected piglets but IFN- $\gamma$ levels were significantly lower $(\mathrm{P}<0.01)$ and IL-4 levels were significantly higher $(\mathrm{P}<0.05)$ in infected piglets than in the controls. Furthermore, lymphocytic apoptosis increased in PCV2b-infected piglets and CD4+ to CD8+ ratios were lower in these piglets than in the controls. These findings suggest vertical transmission of PCV2b to fetuses, leading to an imbalance of intestinal immune function in piglets.
\end{abstract} imbalance

Key words: Porcine circovirus type 2, newborn piglets, intestinal immune

Circoviruses, the smallest animal DNA viruses known to date, have a single-stranded, circular DNA genome that varies in size between $1.7 \mathrm{~kb}$ and $2.3 \mathrm{~kb}$ (Studdert, 1993; Manket et al., 1997). Since the late 1990s, porcine circovirus type 2 (PCV2) has been regarded as the main causative agent of postweaning multisystemic wasting syndrome (PMWS) in pigs (Ellis et al., 1998; Allan et al., 1999). Furthermore, in recent years, PCV2-associated reproductive disorders and enteritis have commonly been observed on PCV2-contaminated swine farms (O’Connor et al., 2001; Hansen et al., 2010; de Castro et al., 2012). Transplacental infection by PCV2 under field conditions was reported by de Castro et al. (2012), who detected a high prevalence of viraemia in sows and in their pre-

\footnotetext{
${ }^{+}$The first author and the second author contributed equally to this work

*Corresponding author; E-mail: zbangd@hunau.edu.cn; Fax: 0086 (0731) 84635276
} 
suckle piglets infected with PCV2a or PCV2b. There are numerous reports on the suppression of immunity induced by PCV2 (West et al., 1990; Kekarainen et al., 2008; Cecere et al., 2012; Marco-Ramell et al., 2014). Moreover, Kawashima et al. (2003) have indicated that cell-mediated immunity plays an important role in immunosuppression in pigs infected with PCV2. Enteritis associated with PCV2 in pigs has also been reported by Kim et al. (2004), who showed that lymphocyte depletion in Peyer's patches is indicative of a direct or indirect pathogenic effect of the virus, suggesting that the intestinal immune system is not functioning properly. However, PCV2-associated enteritis in sucking piglets is less commonly recognised. Experimental confirmation of the ability of PCV2b to induce enteritis is lacking and only few studies have investigated the suppression of intestinal immunity by PCV2 infection during the fetal period (Kim et al., 2004; Bianco et al., 2014). In order to investigate disorders of intestinal immunity in piglets infected by PCV2 during the fetal period, we examined lymphocytic apoptosis, CD4+/CD8+ ratios in the mesenteric lymph nodes (MLNs), and intestinal immunity related factors in PCV2-infected newborn piglets born to sows intramuscularly infected with PCV2b. Piglets born to mock-infected sows served as study controls.

\section{Materials and methods}

\section{Experimental design and animal inoculation}

Five sows [free of PCV2, porcine respiratory and reproductive syndrome virus (PRRSV), pseudorabies virus (PRV) and porcine parvovirus (PPV) and of antibodies against PCV2) were obtained from a pig farm in Huihua, Hunan, China, divided into two groups (three sows in Group 1 and two in Group 2) and artificially inseminated using pathogen-free semen. Each of the three sows in Group 1 was intramuscularly inoculated at day 75 after insemination with $5 \times 10^{6}$ tissue culture infectious doses $\left(\mathrm{TCID}_{50}\right)$ of PCV2b (GenBank accession number: KJ867555) in $5 \mathrm{ml}$ of cell culture supernatant. In Group 2, each of the two sows was infected with cell culture supernatant. Each sow was housed in a separate room and fed a diet of balanced nutrient composition. After delivery, three newborn piglets from each litter ( 9 piglets for the test and 6 piglets for the control group) were randomly selected and euthanised with nitrous oxide $(90 \%)$ and air $(10 \%)$ prior to suckling. Samples of mesenteric lymph nodes (MLNs) and duodena were collected for the detection of PCV2b, lymphocytic apoptosis, intestinal immunity related factors, and secretory immunoglobulin A (SIgA). The study was conducted in accordance with the ethical guidelines for animal care in use in China (IACUC permit no. HNPR-2009-05003). 
PCR assay

PCV2b DNA in MLNs and duodena was extracted using a viral DNA extraction kit (Nanjing Keygen Biotech. Co. Ltd., Nanjing, Jiangsu, China). We used PCV2b-specific primers (forward primer: 5'-CACGGATATTGTATTCCT GGT-3', reverse primer: 5'-CCGCACCTTCGGATATACTG-3') to detect PCV2b DNA in the tissues using the PCR methods described in our previous study (Deng et al., 2013).

\section{Immunohistochemistry}

Mouse anti-PCV2b monoclonal antibody (Abmart Co. Ltd., Shanghai, China) was used as the primary antibody for immunohistochemistry, and antigens of PCV2b in paraffin-embedded tissues were detected using a commercial immunohistochemical (IHC) kit (Zhong Shan Golden Bridge Co. Ltd., Beijing, China) in accordance with the manufacturer's recommendations.

\section{Extraction and purification of lymphocytes from MLNS}

The MLNs were placed into a nylon bag with a 200-mesh sieve and squeezed slightly three times into a plate containing $10 \mathrm{ml}$ Roswell Park Memorial Institute (RPMI) 1640 medium (Invitrogen Corporation, Carlsbad, CA, USA) with $5 \%$ fetal bovine serum and $1 \%$ penicillin/streptomycin. The dispersed lymphocytes were filtered through the wall of the nylon bag by squeezing, and then the cell suspensions were collected for cell labelling and flow cytometry. All the procedures were performed at $5{ }^{\circ} \mathrm{C}$.

\section{Cell labelling and flow cytometry}

Cell suspension samples were centrifuged at $400 \times g$ for $5 \mathrm{~min}$ and the supernatant was discarded. The cell pellet was resuspended to a concentration of $1 \times 10^{5}$ cells $/ \mathrm{ml}$. The cells were then incubated in binding buffer containing propidium iodide and FITC-labelled Annexin V (Life Technologies Co., Carlsbad, CA, USA) for the detection of lymphocytic apoptosis, or diluted to $1 \times 10^{6}$ cells/ml for $\mathrm{CD} 4+$ and $\mathrm{CD} 8+$ cell detection using anti-CD3 [PPT3] $(\mathrm{PE} / \mathrm{Cy} 5 \circ, \mathrm{R})$, anti-CD4 [74-12-4] (FITC), and anti-CD8 antibodies [76-2-11] (FITC) (Abcam Inc., Cambridge, UK). The above-mentioned procedures were performed within 45 min under dark conditions at $4{ }^{\circ} \mathrm{C}$. The processed cells were detected using a flow cytometer (BD Biosciences, San Jose, CA, USA), and the data were evaluated with Tree Star's FlowJo software (v 7.6). 
Extraction of intestinal protein and detection of IL-2, IL-4, IFN- $\gamma$, transforming growth factor- $\beta$ (TGF- $\beta$ ) and $\operatorname{SIg} A$

The duodenal contents were washed off using phosphate-buffered saline (PBS) and $5 \mathrm{~g}$ samples from the duodena were ground to produce a homogenate. Three grams of the tissue homogenate were transferred to a tube containing $7 \mathrm{ml}$ PBS (for cytokine detection), and $0.1 \mathrm{~g}$ of homogenate was placed into a tube containing $1 \mathrm{ml}$ PBS (for SIgA detection). These samples were then twice frozen at $-80{ }^{\circ} \mathrm{C}$ and thawed at room temperature. Thereafter, the samples were centrifuged at $4000 \times \mathrm{g}$ for $5 \mathrm{~min}$ at $4{ }^{\circ} \mathrm{C}$. The supernatant was collected for the detection of intestinal IL-2, IL-4, IL-10, IFN- $\gamma$ and TGF- $\beta$ using commercial kits (Uscn Life Science Inc., Wuhan, China). SIgA was detected using an SIgA kit (Uscn Life Science Inc., Wuhan, China). Absorbances $(450 \mathrm{~nm})$ were measured using an ELISA reader (Infinite ${ }^{\circledR} 200$ PRO NanoQuant - Tecan, Männedorf, Switzerland). Standard curves for each cytokine and SIgA were prepared using standard samples of cytokines and SIgA (provided by the manufacturer in kits) and the professional software Curve Expert 1.3 (which generates a graph of absorbance on the $y$-axis versus concentration on the $\mathrm{x}$-axis) in accordance with the manufacturer's instructions. Cytokine and SIgA concentrations were calculated from the standard curves using Curve Expert 1.3, and the data were analysed using SPSS 17.0.

\section{Results}

\section{Gross and histopathological lesions}

With the exception of a few lymph nodes that appeared mildly swollen, no gross lesions were observed in the MLNs and intestines derived from PCV2binfected newborn piglets. Histopathological lesions in the MLNs mainly manifested as lymphocytic apoptosis and depletion in the germinal centres of lymph nodes (Fig. 1A); however, no histopathological lesions were observed in the intestines. No gross or histopathological lesions were observed in the control piglets.

\section{PCR and immunohistochemical assays}

The PCR results showed that PCV2b DNA was detected in 9/9 MLNs and $8 / 9$ duodena from PCV2b-infected newborn piglets. In immunohistochemical assays, PCV2b antigen was detected in many lymphocytes of the germinal centres of MLNs (Fig. 1C), and a small number of lymphocytes with PCV2b antigen were observed in the paracortical and medullary areas of lymph nodes. No PCV2b DNA and virus antigen signals were detected in the controls. 
INTESTINAL IMMUNE FUNCTION IN PIGLETS INFECTED BY PCV2 IN THE FETAL PERIOD 139

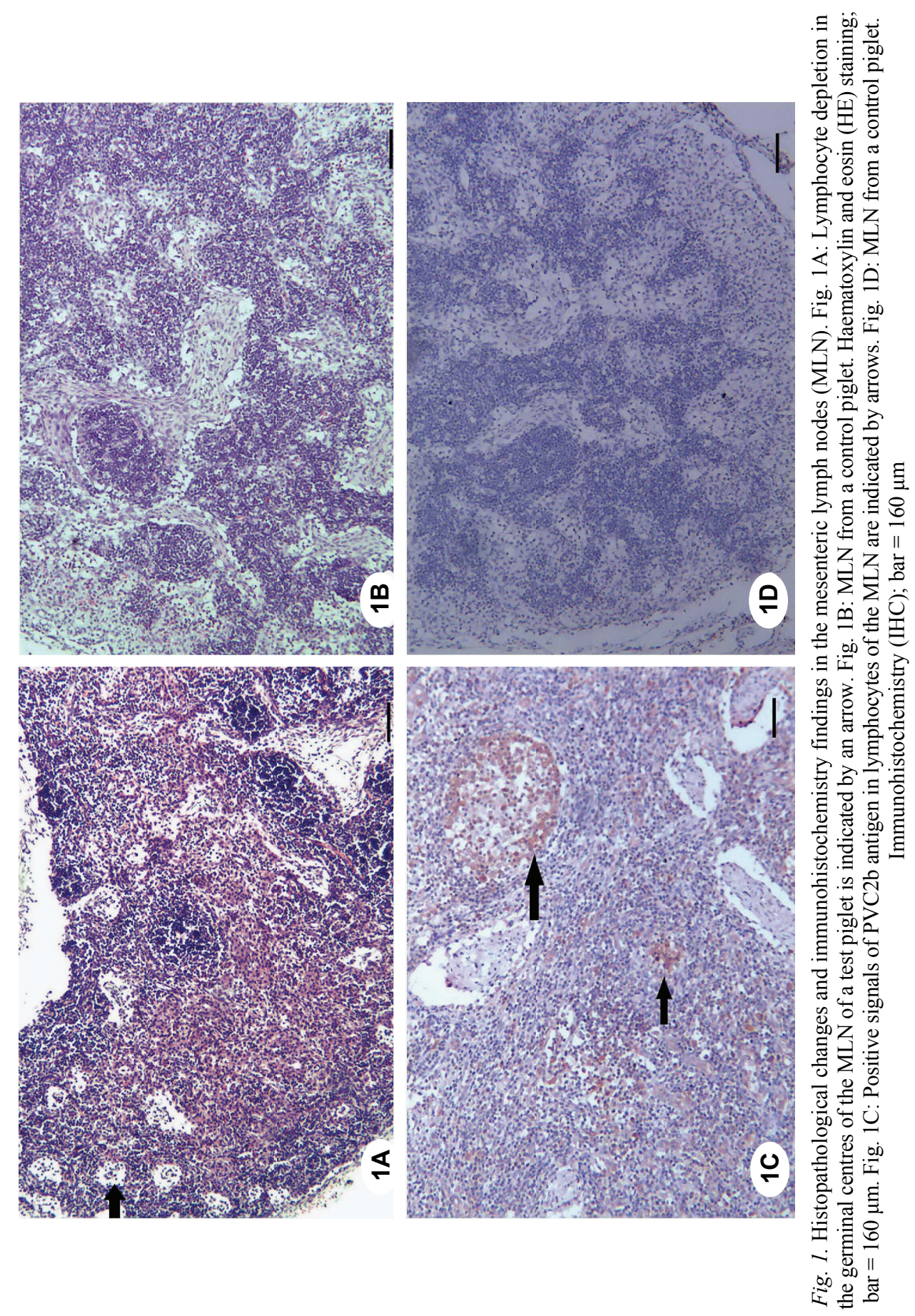




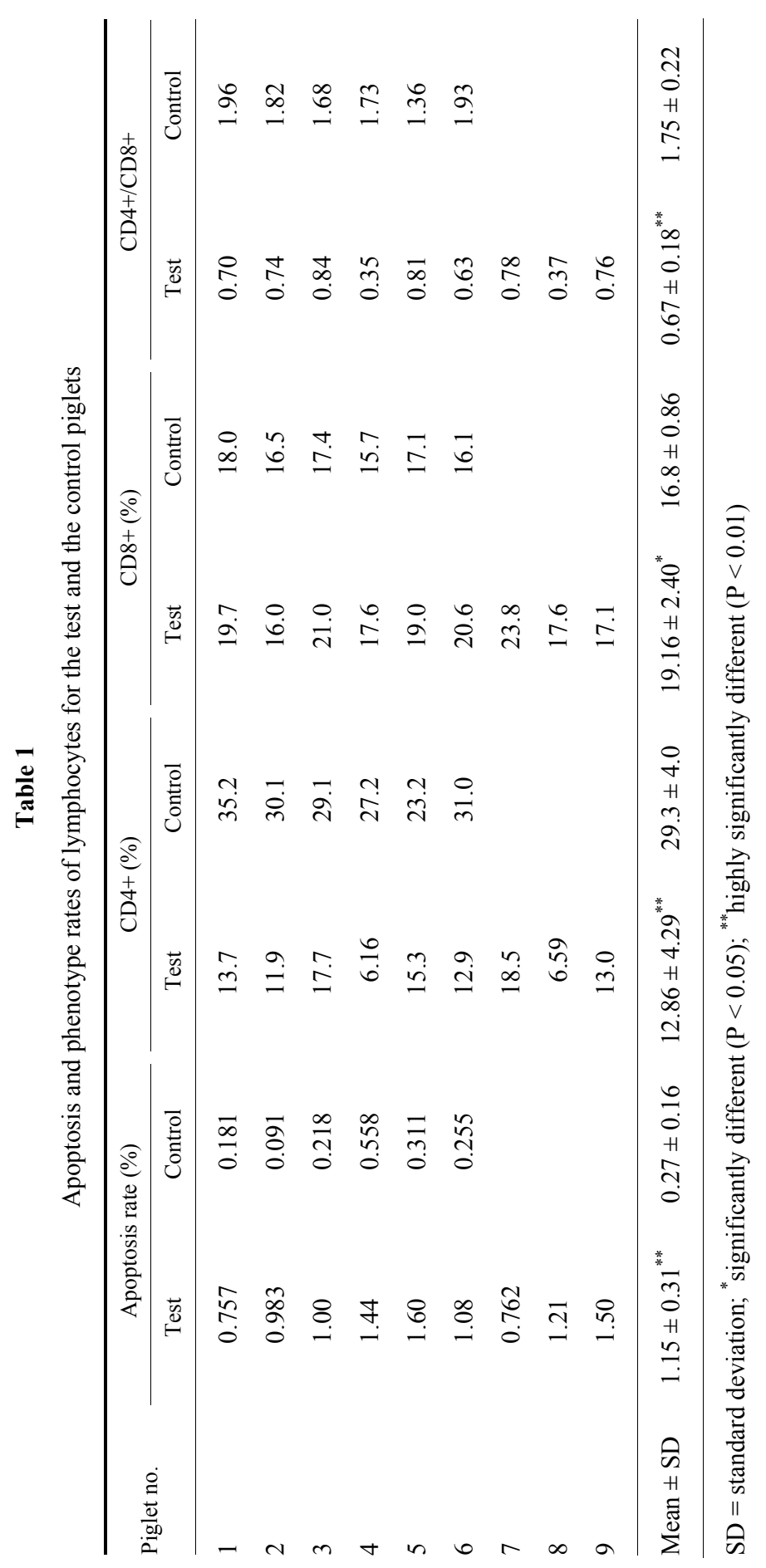



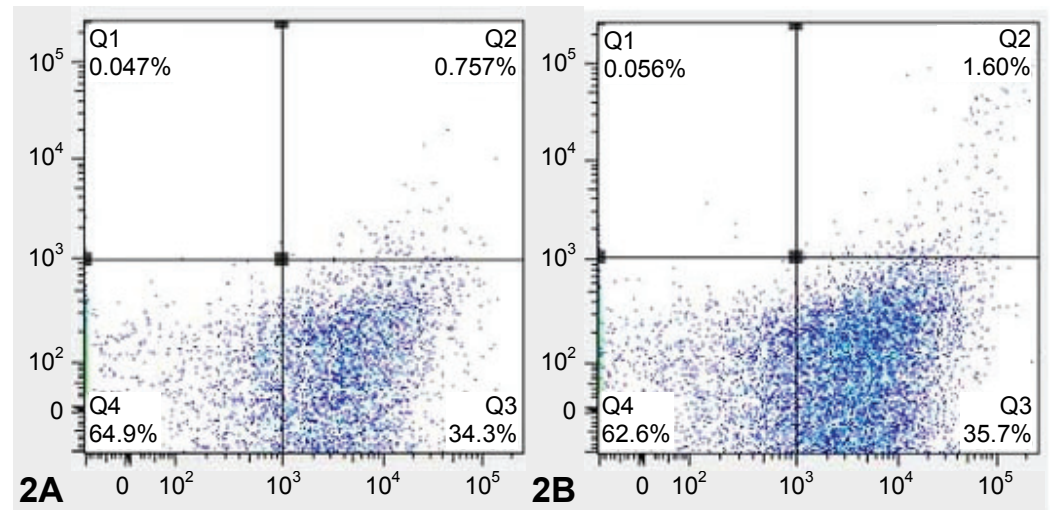

2A $10^{3}$ $10^{4}$ $10^{5}$
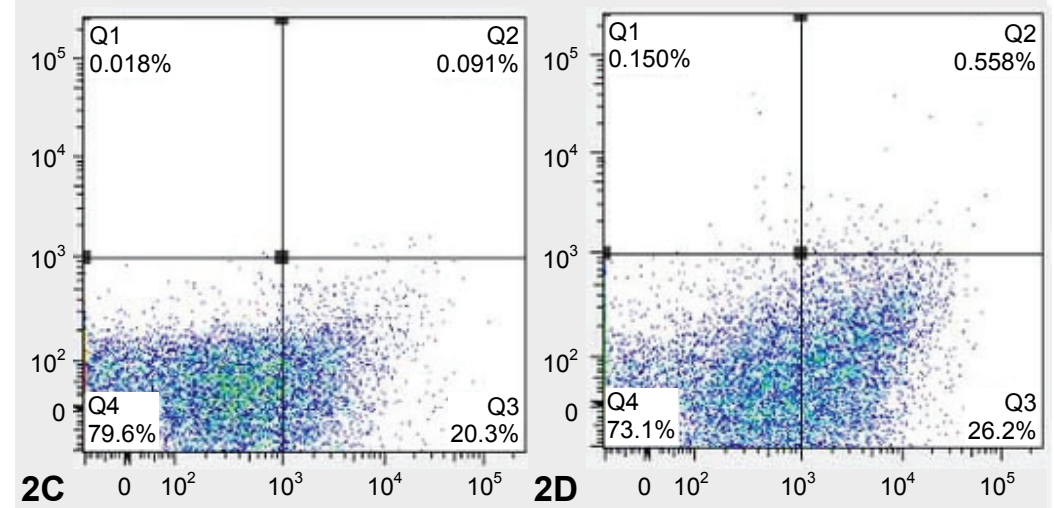

Fig. 2. Detection of lymphocyte apoptosis using flow cytometry. Figs $2 \mathrm{~A}$ and $2 \mathrm{~B}$ show the lowest and the highest apoptotic rates of MLN lymphocytes in the test piglets, respectively. Figs $2 \mathrm{C}$ and 2D show the lowest and the highest apoptotic rates of MLN lymphocytes in the control piglets, respectively

\section{Apoptosis and phenotype rates of lymphocytes}

The apoptosis rates of lymphocytes in the MLNs were $0.757-1.60 \%$ for the PCV2b-infected piglets and $0.091-0.558 \%$ for the control piglets (data shown in Table 1 and Fig. 2). Statistical analysis showed that the apoptosis rates of lymphocytes were significantly higher in the virus-infected piglets than in the controls $(\mathrm{P}<0.01)$. The percentage of $\mathrm{CD} 8+$ was increased $(\mathrm{P}<0.05)$, whereas that of $\mathrm{CD} 4+$ was decreased $(\mathrm{P}<0.01)$, resulting in significantly lower $\mathrm{CD} 4+$ / $\mathrm{CD} 8+$ values in the virus-infected piglets than in the controls $(\mathrm{P}<0.01)$ (data shown in Table 1 and Fig 3).

\section{$I L-2, I L-4, I L-10, I F N-\gamma, T G F-\beta$ and SIgA levels}

The data pertaining to cytokines and SIgA are shown in Table 2. IFN- $\gamma$ levels were significantly lower $(\mathrm{P}<0.01)$ while IL-4 levels were significantly 
higher $(\mathrm{P}<0.05)$ in virus-infected piglets than in the controls. In contrast, although the levels of IL-2, IL-10 and TGF- $\beta$ were lower in infected piglets than in the controls, the differences were not significant. SIgA levels were significantly higher $(\mathrm{P}<0.01)$ in infected piglets than in the controls.

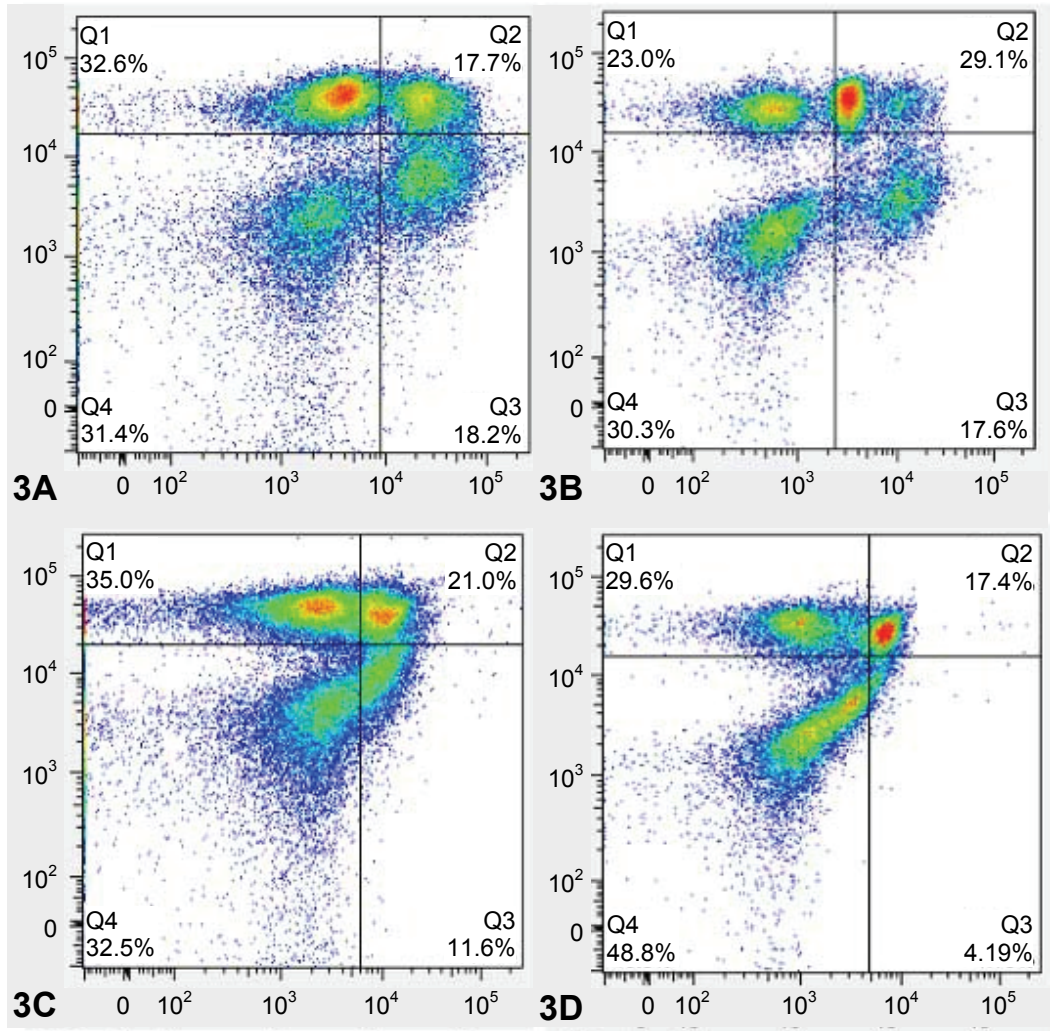

Fig. 3. Detection of the phenotype of lymphocytes using flow cytometry. Figs 3A and 3B show the percentages of CD4+ in test piglet no. 3 and control piglet no. 3, respectively. Figs 3C and 3D show the percentages of CD $8+$ in test piglet no. 3 and control piglet no. 3 , respectively

\section{Discussion}

PCV2-induced enteric immune dysfunction in piglets is currently a notable problem (Baró et al., 2015). PCV2 can induce enteritis independently of other enteric pathogens, and has a major contribution to enteric clinical disorders related to the occurrence of PCV2-systemic disease (PCV2-SD) (Opriessnig et al., 2011; Baró et al., 2015). However, PCV2-associated enteritis in sucking piglets is less commonly recognised, and studies that confirm the ability of PCV2 to induce enteritis are lacking. In this study, although the PCV2b-infected piglets showed 
INTESTINAL IMMUNE FUNCTION IN PIGLETS INFECTED BY PCV2 IN THE FETAL PERIOD 143

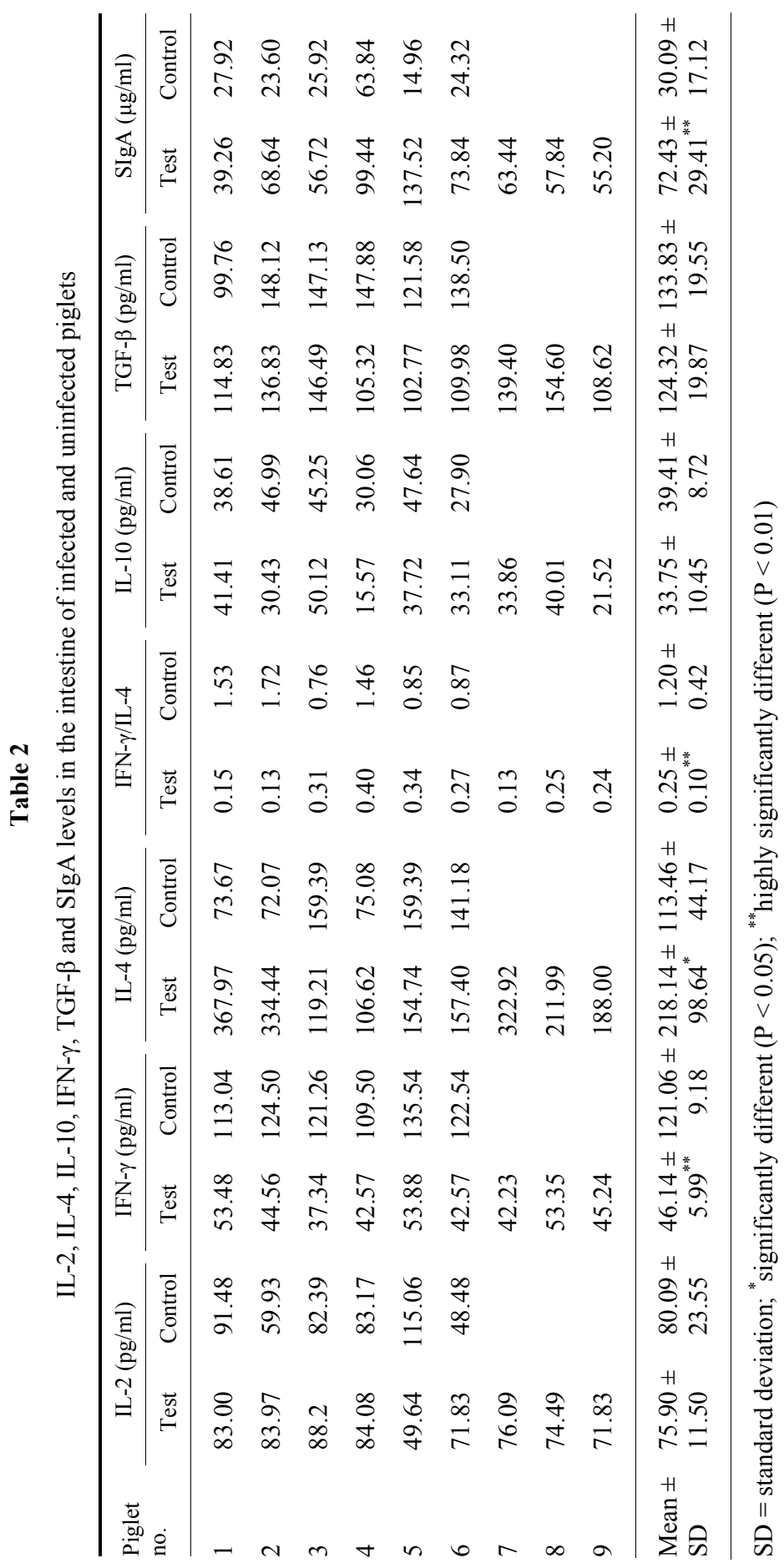


no clinical signs (were in subclinical condition), lymphocytic apoptosis or depletion increased in these piglets, and the ratios of CD4+ to CD8+ were lower than in the controls. These findings are suggestive of immunosuppression in the organism, and a resulting lack of immune surveillance in the intestinal mucosa.

In addition to digestion, the intestines are also involved in hormone secretion and immune regulation (Abreu, 2010). The MLNs and gut-associated lymphoid tissues (GALTs) play an important role in immune defence in the intestine. In addition, cytokines, which are secreted by lymphocytes, can maintain and regulate the immune function in a healthy physiological state. Compared to the jejunum and ileum, the duodenum has abundant GALTs and fewer intestinal tract microorganisms. Accordingly, we used duodenum samples in the present study for the detection of cytokines and SIgA.

Although the PCV2b-infected piglets showed no significant changes in the levels of IL-2, IL-10 and TGF- $\beta$ when compared with the control animals, the IFN- $\gamma$ levels of infected piglets were significantly lower and their IL-4 levels were significantly higher. CD4+ T cells (T helper lymphocytes) include Th1 and Th2. Th1 cells produce IFN- $\gamma$ that plays a critical role in the promotion of cellular immunity, whereas Th2 cells secrete IL-4, which is related to humoral immunity. The ratio of Th1 and Th2 changes as a result of virus infection. In combination with the changes of IFN- $\gamma$ and IL-4 shown in the present study, it is suggested that there is a Th1 to Th2 shift triggering immunosuppression in the intestines of infected piglets.

In this study we found increased lymphocyte apoptosis and decreased CD4+/CD8+ and Th1/Th2 ratios in PCV2-infected piglets. The possible mechanism of these immunological changes is related to the expression of immunerelated genes and proteins. By RNA sequence analysis of lymphocytes in the MLNs of test and control piglets, 2 cell apoptosis-related genes and 9 immunerelated genes (data not shown) were found and had differential expression, such as FOS and CCL17. The FOS gene is associated with cell apoptosis or death and may induce lymphocyte apoptosis, while the product of CCL17 binds to chemokine receptors CCR4 and CCR8; these chemokines play important roles in $\mathrm{T}$ cell development in the thymus as well as in trafficking and activation of mature $\mathrm{T}$ cells, thereby resulting in a change of the $\mathrm{CD} 4+/ \mathrm{CD} 8+$ ratio.

SIgA is the main antibody of the mucosal immune system and plays a key role in humoral immunity, acting as a first line of defence that prevents pathogenic bacteria from infecting the intestinal mucosa. Generally, if animals are infected by intestinal pathogens or are administered oral vaccines, the levels of SIgA will increase. In this study, the levels of SIgA were significantly higher in the infected piglets than in the controls, which is somewhat inconsistent with the findings reported by Marco-Ramell et al. (2014) and Bianco et al. (2014). As an explanation for this discrepancy in observations between studies, we suggest that although PCV2 is an immunosuppressive pathogen, its immune activating effect 
in the intestinal mucosa system may occur prior to the development of immunologic changes during the early period of virus infection. Furthermore, increased IL-4 contributes to SIgA secretion in the intestinal mucosa.

In conclusion, it is generally known that PCV2 is transmitted vertically from sows to their fetuses and causes immunosuppression in newborn piglets. The increased lymphocyte apoptosis and decreased CD4+/CD8+ and Th1/Th2 ratios in PCV2-infected piglets might indicate an imbalance of intestinal immune function during PCV2b infection in the fetal period. Thus, to protect sucking piglets from PCV2 infection, vaccination is critically important for sows and their piglets.

\section{Acknowledgements}

This project was supported by the General Program of the National Natural Science Foundation of China (grant no. 31372406), the Hunan Provincial Natural Science Foundation of China (grant no. 2015JJ2082) and the Research Foundation of Hunan Provincial Education Department, China (Grant no. 15A086).

\section{References}

Abreu, M. T. (2010): Toll-like receptor signalling in the intestinal epithelium: how bacterial recognition shapes intestinal function. Nat. Rev. Immunol. 10, 131-143.

Allan, G. M., McNeilly, F., Meehan, B. M., Kennedy, S., Mackie, D. P., Ellis, J. A., Clark, E. G., Espuna, E., Saubi, N., Riera, P., Botner, A. and Charreyre, C. E. (1999): Isolation and characterisation of circoviruses from pigs with wasting syndromes in Spain, Denmark and Northern Ireland. Vet. Microbiol. 66, 115-123.

Baró, J., Segalés, J. and Martínez, J. (2015): Porcine circovirus type 2 (PCV2) enteric disease: an independent condition or part of the systemic disease? Vet. Microbiol. 176, 83-87.

Bianco, C., Felice, V., Panarese, S., Marrocco, R., Ostanello, F., Brunetti, B., Muscatello, L. V., Leotti, G., Vila, T., Joisel, F. and Sarli, G. (2014): Quantitative immunohistochemical assessment of IgA, IgM, IgG and antigen-specific immunoglobulin secreting plasma cells in pig small intestinal lamina propria. Vet. Immunol. Immunopathol. 160, 281-287.

Cecere, T. E., Meng, X. J., Pelzer, K., Todd, S. M., Beach, N. M., Ni, Y. Y. and Leroith, T. (2012): Co-infection of porcine dendritic cells with porcine circovirus type 2a (PCV2a) and genotype II porcine reproductive and respiratory syndrome virus (PRRSV) induces CD4(+) CD25(+) FoxP3(+) T cells in vitro. Vet. Microbiol. 160, 233-239.

de Castro, A. M., Cruz, T. F., Salgado, V. R., Kanashiro, T. M., Ferrari, K. L., Brandão, P. E. and Richtzenhain, L. J. (2012): Detection of porcine circovirus genotypes $2 \mathrm{a}$ and $2 \mathrm{~b}$ in aborted foetuses from infected swine herds in the State of São Paulo, Brazil. Acta Vet. Scand. 54, 29.

Deng, Z. B., Yuan, A. W., Luo, W., Wang, N. D., Gong, Q. L., Yu, X. L. and Xue, L. Q. (2013): Transmission of porcine circovirus type $2 \mathrm{~b}$ (PCV2b) in Kunming mice. Acta Vet. Hung. 61, 234-243.

Ellis, J., Hassard, L., Clark, E., Harding, J., Allan, G., Willson, P., Strokappe, J., Martin, K., McNeilly, F., Meehan, B., Todd, D. and Haines, D. (1998): Isolation of circovirus form lesions of pigs with postweaning multisystemic wasting syndrome. Can. Vet. J. 39, 44-51. 
Hansen, M. S., Hjulsager, C. K., Bille-Hansen, V., Hauqeqaard, S., Dupont, K., Hoqedal, P., Kunstmann, L. and Larsen, L. E. (2010): Selection of method is crucial for the diagnosis of porcine circovirus type 2 associated reproductive failures. Vet. Microbiol. 144, 203-209.

Kawashima, K., Tsunemitsu, H., Horino, R., Katsuda, K., Onodera, T., Shoji, T., Kubo, M., Haritani, M. and Murakami, Y. (2003): Effects of dexamethasone on the pathogenesis of porcine circovirus type 2 infection in piglets. J. Comp. Pathol. 129, 294-302.

Kekarainen, T., Montoya, M., Mateu, E. and Segalés, E. (2008): Porcine circovirus type 2 induced interleukin-10 modulates recall antigen responses. J. Gen. Virol. 89, 760-765.

Kim, J., Ha, Y., Jung, K., Choi, C. and Chae, C. (2004): Enteritis associated with porcine circovirus 2 in pigs. Can. J. Vet. Res. 68, 218-221.

Manket, A., Persson, F., Mankertz, J., Blaess, G. and Buhk, H. J. (1997): Mapping and characterization of the origin of DNA replication of porcine circovirus. J. Virol. 71, 2562-2566.

Marco-Ramell, A., Miller, I., Nöbauer, K., Möginger, U., Segalés, J., Razzazi-Fazeli, E., Kolarich, D. and Bassols, A. (2014): Proteomics on porcine haptoglobin and IgG/IgA show protein species distribution and glycosylation pattern to remain similar in PCV2-SD infection. J. Proteomics 101, 205-216.

O’Connor, B., Gauvreau, H., West, K., Bogdan, J., Ayroud, M., Clark, E. G., Konoby, C., Allan, G. and Ellis, J. A. (2001): Multiple porcine circovirus 2-associated abortions and reproductive failure in a multisite swine production unit. Can. Vet. J. 42, 551-553.

Opriessnig, T., Madson, D. M., Roof, M., Layton, S. M., Ramamoorthy, S., Meng, X. J. and Halbur, P. G. (2011): Experimental reproduction of porcine circovirus type 2 (PCV2)associated enteritis in pigs infected with PCV2 alone or concurrently with Lawsonia intracellularis or Salmonella typhimurium. J. Comp. Pathol. 145, 261-270.

Studdert, M. J. (1993): Circoviridae: new viruses of pigs, parrots and chickens. Aust. Vet. J. 70, 121-122.

West, K. H., Bystrom, J. M., Wojnarowicz, C., Shantz, N., Jacobson, M., Allan, G. M., Haines, D. M., Clark, E. G., Krakowka, S., McNeilly, F., Konoby, C., Martin, K. and Ellis, J. A. (1990): Myocarditis and abortion associated with intrauterine infection of sows with porcine circovirus 2. J. Vet. Diagn. Invest. 11, 530-532. 